\title{
The Conformity of Anatomical Pathology Results between Core-Needle Biopsy and Fine-Needle Aspirate Biopsy in Peripheral Lung Tumors
}

\author{
Kadek Widianiti ${ }^{1}$, Isnin Anang Marhana ${ }^{2}$, Etty Hary Kusumastuti ${ }^{3}$ \\ ${ }^{1}$ Resident, ${ }^{2}$ Lecturer, Department of Pulmonology and Respiratory Medicine, Faculty of Medicine, ${ }^{3}$ Lecturer, \\ Department of Anatomical Pathology, Faculty of Medicine, Universitas Airlangga - Dr. Soetomo General \\ Academic Hospital, Surabaya, Indonesia
}

\begin{abstract}
Backgroud: The problem of diagnostic lung tumor is a challenge for clinicians, especially pulmonologists in determining the definitive diagnosis of a lung tumor.

Objective: To analyze the suitability of the results of anatomic pathology between Core-Needle Biopsy (CNB) and Fine-Needle Aspirate Biopsy (FNAB) in peripheral lung tumors.

Method: The design of this study used a cross-sectional study which was conducted in the period September 2019-December 2020. Participants are examined by CNB and FNAB at one time. Statistical analysis used the Kappa test with $\mathrm{p}<0.05$.

Result: Most of the tumor locations were in the superior lobe of the right lung which had FNAB results in the category of malignancy (39.5\%), non-malignant (30.0\%), and undiagnosed $(27.8 \% ; \mathrm{p}=0.306)$. Meanwhile, in CNB, most of the tumor locations in the superior lobe of the right lung had CNB results in the malignant category $(34.4 \%)$, non-malignancy $(26.7 \%)$, and undiagnosed $(75.0 \% ; \mathrm{p}=0.240)$. Comparison of the results of the anatomical pathology from the FNAB and CNB materials in the malignance category as many as 35 participants (74.5\%), 7 participants (53.8\%) and undiagnosed non-malignancies with 4 participants (16.7\%) with an accuracy of $69.69 \%(K=0.43 ; p=0.001)$.
\end{abstract}

Conclusion: There is a sufficient degree of agreement between the anatomical pathology results of the FNAB and CNB materials for the diagnosis of peripheral lung tumors.

Keywords: core-needle biopsy, fine-needle aspirate biopsy, peripheral lung tumors

\section{Introduction}

The problem of lung tumor diagnostic enforcement

\section{Corresponding Author:}

Isnin Anang Marhana

Department of Pulmonology and Respiratory Medicine, Faculty of Medicine, Universitas Airlangga - Dr.

Soetomo General Academic Hospital, Jl. Mayjend Prof. Dr. Moestopo No. 6-8, Airlangga, Gubeng, Surabaya, East Java 60286, Indonesia

E-Mail: marhanadr@gmail.com; inatime2019b@gmail.com is a challenge for clinicians, especially pulmonologists in determining the definitive diagnosis of a lung tumor, the first is because generally patients arrive at an advanced stage with the patient's physical limitations in carrying out invasive diagnostic procedures and the second challenge is when the patient is able to undergo the diagnostic procedure. However, a further problem was faced with insufficient diagnostic specimens from pulmonary tumor material obtained for morphological examination by anatomical pathology colleagues. Diagnostic modalities for peripheral pulmonary lesions 
include traditional and advanced techniques. Traditional diagnostic techniques consist of a percutaneous biopsy technique with Transthoracic Needle Aspiration (TTNA) known as Fine Needle Aspirate Biopsy (FNAB) and bronchoscopy, while advanced techniques include Endobronchial Ultrasound (EBUS) and Electromagnetic Navigation Bronchoscopy (ENB) ${ }^{(1)}$.

Today, imaging-guided percutaneous needle biopsy is generally recognized to play an important role in the diagnosis of various lung lesions with high diagnostic performance and safety. A thoracic ultrasound-guided percutaneous needle biopsy (USG) is reported to be as safe and effective as a thoracic guided computed tomography (CT) scan in guiding a percutaneous needle biopsy especially in peripheral lung tumors adhering to the chest wall ${ }^{(1)}$.

Fine needle aspiration biopsy or known as FNAB has been recognized as the initial diagnostic tool for all body lesions, whether benign or malignant. In some cases there are limitations and shortcomings where the cytological sample from the FNAB material is insufficient to determine a definitive diagnosis of the lung tumor, so the patient has to undergo other diagnostic procedures, namely performing a further procedure in the form of a repeat FNAB, biopsy using a larger core needle ( Core Needle Biopsy / CNB) or open biopsy. This follow-up action does not rule out the possibility of causing the patient to become uncomfortable, extending the treatment period and leading to more expensive treatment $\operatorname{costs}^{(2,3)}$.

In several hospital center services, it has been reported that FNAB action which is immediately followed by CNB at the same time has been implemented and shows several advantages when this biopsy procedure is combined in one time which includes: (a) Time efficiency where the patient comes in one visit and obtaining both procedures (b) The specimens obtained by the two procedures are more adequate, representative and complementary to enable the anatomical pathologist to reach an accurate diagnosis (c) Cost-effective as hopefully avoiding a second, potentially more invasive diagnostic procedure $^{(3,4)}$.

A biopsy with a thoracic ultrasound guide as a guide can be performed without the need for a special room and equipment that can be easily carried to the patient's bedside. In this context, thoracic ultrasound is aspired to be an alternative as a guide to percutaneous biopsy, especially in peripheral thoracic lesions that can offer important information, especially peripheral lung lesions ${ }^{(5,6)}$. Based on the description above we are interested in evaluating the suitability of the CNB and FNAB results with the aid of thoracic ultrasound in peripheral lung tumors.

\section{Method}

Participants in this study were lung tumor patients who met the inclusion and exclusion criteria. Participant inclusion criteria included patients with features of peripheral lung tumors on chest X-ray and chest CT scans, and a percutaneous biopsy was performed using the assisted thoracic ultrasound guidance. Participants' exclusion criteria included patients with a performance score $<50$ or hemodynamically unstable, massive pleural effusions that had not been treated, medastinal tumors, central lung tumors, concomitant lung disease conditions, hemostatic physiological disorders, and anatomical pathology results either biopsy or FNAB or CNB's not out.

The research design used a cross-sectional study in which this research was conducted in Dr. Soetomo General Academic Hospital. This research was conducted in the period September 2019 - December 2020. The number of participants in this study was 66 . This study uses 2 variables, namely CNB and FNAB. FNAB is a diagnostic procedure in the form of a percutaneous biopsy of the thoracic region using a fine 25 gauge needle. CNB is a diagnostic procedure in the form of a percutaneous biopsy in the thoracic region using a 14 gauge core needle with the tip of the needle serving as a cutter.

The FNAB sampling technique is by laying the patient on the acting table, determining the location 
to be biopsied, disinfecting the skin in the area to be biopsied with $10 \%$ povidone iodine followed by $70 \%$ alcohol, placing a sterile duk, performing $2 \%$ lidocain infiltration (1-2 cc) at the site of the biopsy, intrakutan, subcutaneously until it reaches the parietal pleura, performs a vertical spinal needle puncture until it reaches the lesion. The stylet is taken, the needle is connected with a $20 \mathrm{cc}$ syringe, the suction is firmly pulled, the needle is moved up and down along $0.5-1 \mathrm{~cm}$ several times. The suction is returned to its original position slowly, the needle is removed. The biopsy material that has been aspirated is removed onto the slide, immediately made a flat smear, fixed then dried. If necessary this procedure can be repeated a second or third time according to the initial assessment by the anatomical pathology colleague in assessing the adequacy of the specimen.

The CNB sampling technique is by inserting a core needle at the same location at the previous FNAB needle point until it reaches the lesion according to the depth of the thoracic ultrasound. The biopsy material that has been cut through the core is removed into the slide, immediately made a flat smear, fixed then dried. If necessary this procedure can be repeated a second or third time according to the initial assessment by the anatomical pathology colleague in assessing the adequacy of the specimen. Then make post-biopsy observations for inpatients while in the room. For outpatients, observation is carried out for 2 hours, if there are no complications, the patient is allowed to go home with advice to return immediately if he has symptoms of shortness of breath or coughing up severe blood.

Measurement data were analyzed univariate and bivariate, where univariate data were displayed in the form of a frequency distribution or mean \pm standard deviation (SD). Measurement data were analyzed using IBM SPSS Statistics software version 21.0 (IBM Corp., Armonk, NY, USA). The statistical analysis in this study used the Kappa test with a $\mathrm{p}$ value $<0.05$ which was considered significant.

\section{Result}

\section{Participant Characteristics}

Most of the participants were male (81.8\%), aged $>50$ years $(77.3 \%)$, the most common respiratory symptom was chronic cough (63.6\%). Most of the tumors were in the right lung $(62.1 \%)$ and most were in the right superior lobe (34.8\%). Most of the participants performed anterior needle insertion (66.7\%). Most tumors measuring $>70 \mathrm{~mm}$ were $39.4 \%$ and the majority of participants did not experience post-FNAB and CNB complications (95.5\%; Table 1).

The majority of the participants underwent 2 stabs in each technique, namely the FNAB (93.9\%) and the CNB technique (63.6\%). In both groups, the results of malignant anatomic pathology were found, in which FNAB was $57.6 \%$ and $C N B$ was $71.2 \%$. The ingredients in both groups were declared adequate, with FNAB as much as $72.7 \%$ and CNB as much as $89.4 \%$ (Table 2).

\section{Correlation of tumor size, age, and number of} punctures on complications of post-FNAB and CNB

Most of the participants had a tumor size $>70 \mathrm{~mm}$ in diameter, 23 participants (36.5\%) had no complications, however, $3.8 \%$ had hemoptysis and $7.7 \%$ had pneumothorax $(p=0.857)$. Most of the participants who did not experience complications were above $>50$ years old as much as $96 \%$, but there were still participants who experienced hemoptysis $(2 \%)$ and pneumothorax $(2 \%)$ who were also $>50$ years old $(\mathrm{p}=0.198)$. The majority of FNAB participants did not experience complications with 2 stabbing as much as $95.2 \%(p=1,000)$ and the CNB participants did not experience complications with more than 2 stabbing as many as $87.5 \%$, but there were still incidents of pneumothorax and hemoptysis with more than 2 punctures. $(\mathrm{p}=0.040$; table 3$)$.

\section{Correlation between lung tumor size and location} with FNAB and CNB on pathological anatomical findings

The most participant tumor size $>70 \mathrm{~mm}$ had a FNAB result in the category of malignancy (39.5\%), non-malignant $(40.0 \%)$, and undiagnosed $(38.9 \%)$ with a value of $\mathrm{p}=0.757$. Meanwhile, the CNB results were categorized as malignant $(40.4 \%)$, non-malignant 
$(33.3 \%)$ and undiagnosed $(7.6 \%)$ with $\mathrm{p}$ value $=0.510$. Most of the tumor locations were in the superior lobe of the right lung which had a malignant (39.5\%), nonmalignant (30.0\%), and undiagnosed (27.8\%) FNAB category with $\mathrm{p}$ value $=0.306$. Whereas the most CNB tumor locations in the superior lobe of the right lung had CNB results in the malignant category (34.4\%), non-malignant $(26.7 \%)$, and undiagnosed (75.0\%) with $\mathrm{p}$ value $=0.240$. The level of conformity (not a comparative study but conformity test) of the anatomical pathology results from the FNAB and CNB material in the malignance category was 35 participants $(92.1 \%), 7$ participants $(70 \%)$ were not diagnosed and 4 participants $(11.2 \%)$ were not diagnosed the value $\mathrm{K}=0.43$ ( $\mathrm{p}=$ 0.001 ; table 4$)$. The accuracy value of the suitability of the results of the anatomical pathology of the two techniques was $69.69 \%$.

Table 1. Karakteristik participant

\begin{tabular}{|c|c|}
\hline Variable & n (\%) \\
\hline $\begin{array}{c}\text { Jenis kelamin } \\
\text { Male } \\
\text { Female }\end{array}$ & $\begin{array}{l}54(81.8) \\
12(18.2)\end{array}$ \\
\hline $\begin{array}{c}\text { Age } \\
\text { 20-30 years old } \\
\text { 31-40 years old } \\
\text { 41-50 years old } \\
>51 \text { years old }\end{array}$ & $\begin{array}{c}2(3.0) \\
2(3.0) \\
11(16.7) \\
51(77.3)\end{array}$ \\
\hline $\begin{array}{l}\text { Location of the tumor } \\
\text { Right lung } \\
\text { Left lung }\end{array}$ & $\begin{array}{l}41(62.1) \\
25(37.9)\end{array}$ \\
\hline $\begin{array}{l}\text { Location of the Lung Lobes } \\
\text { Right lung superior lobe } \\
\text { Right pulmonary medius lobe } \\
\text { The inferior lobe of the right lung } \\
\text { Left superior lobe of the lung } \\
\text { Left pulmonary inferior lobe } \\
>1 \text { right lung lobe } \\
>1 \text { left lung lobe }\end{array}$ & $\begin{aligned} 23 & (34.8) \\
6 & (9.1) \\
6 & (9.1) \\
20 & (30.3) \\
2 & (3.0) \\
5 & (7.6) \\
4 & (6.1)\end{aligned}$ \\
\hline $\begin{array}{c}\text { Needle access } \\
\text { Anterior } \\
\text { Posterior } \\
\text { Lateral }\end{array}$ & $\begin{array}{c}44(66.7) \\
20(30.3) \\
2(3.0)\end{array}$ \\
\hline $\begin{array}{l}\text { Tumor size } \\
21-30 \mathrm{~mm} \\
31-40 \mathrm{~mm} \\
41-50 \mathrm{~mm} \\
51-60 \mathrm{~mm} \\
61-70 \mathrm{~mm} \\
>70 \mathrm{~mm}\end{array}$ & $\begin{array}{c}2(3.0) \\
7(10.6) \\
1(1.5) \\
18(27.3) \\
12(18.2) \\
26(39.4)\end{array}$ \\
\hline $\begin{array}{l}\text { Complications } \\
\text { Hemoptysis } \\
\text { Pneumothorac } \\
\text { Nothing }\end{array}$ & $\begin{array}{c}1(1.5) \\
2(3.0) \\
63(95.5)\end{array}$ \\
\hline
\end{tabular}


Table 2. Characteristic differences between DNA and CNB

\begin{tabular}{|c|c|c|}
\hline Variable & FNAB & CNB \\
\hline $\begin{array}{c}\text { Number of Punctures } \\
2 \text { times } \\
>2 \text { times }\end{array}$ & $\begin{array}{c}62(93.9) \\
4(6.1)\end{array}$ & $\begin{array}{l}42(63.6) \\
24(36.4)\end{array}$ \\
\hline $\begin{array}{c}\text { Findings } \\
\text { Malignation } \\
\text { Non malignant } \\
\text { Undiagnosed }\end{array}$ & $\begin{array}{l}38(57.6) \\
10(15.2) \\
18(27.3)\end{array}$ & $\begin{array}{c}47(71.2) \\
13(19.7) \\
6(9.1)\end{array}$ \\
\hline $\begin{array}{c}\text { Results of Anatomical Pathology } \\
\text { Malignance } \\
\text { Squamous cell carcinoma } \\
\text { Adenocarcinoma } \\
\text { Small cell carcinoma } \\
\text { Atypic cells } \\
\text { Metastasis } \\
\text { Malignant round tumor cells } \\
\text { Non malignant } \\
\text { Granulomatous inflammation } \\
\text { Non specific chronic inflammation } \\
\text { Undiagnosed } \\
\text { Not representative /necrosis }\end{array}$ & $\begin{array}{c}5(7.6) \\
19(28.8) \\
0(0.0) \\
8(12.1) \\
1(1.5) \\
5(7.6) \\
1(1.5) \\
9(13.6) \\
18(27.3)\end{array}$ & $\begin{array}{c}9(13.6) \\
25(37.9) \\
5(7.6) \\
1(1.5) \\
5(7.6) \\
1(1.5) \\
4(6.1) \\
9(13.6) \\
7(10.6)\end{array}$ \\
\hline $\begin{array}{c}\text { Adequacy of Materials } \\
\text { Adequate material } \\
\text { Inadequate material }\end{array}$ & $\begin{array}{l}48(72.7) \\
18(27.3)\end{array}$ & $\begin{array}{c}59(89.4) \\
7(10.6)\end{array}$ \\
\hline
\end{tabular}

Table 3. Complications of patients with FNAB and CNB

\begin{tabular}{|c|c|c|c|c|}
\hline \multirow[b]{2}{*}{ Variable } & \multicolumn{3}{|c|}{ Complications } & \multirow[b]{2}{*}{$\mathbf{p}$} \\
\hline & Hemoptysis & Pneumothorac & Nothing & \\
\hline $\begin{array}{c}\text { Tumor size } \\
21-30 \mathrm{~mm} \\
31-40 \mathrm{~mm} \\
41-50 \mathrm{~mm} \\
51-60 \mathrm{~mm} \\
61-70 \mathrm{~mm} \\
>70 \mathrm{~mm}\end{array}$ & $\begin{array}{c}0(0.0) \\
0(0.0) \\
0(0.0) \\
0(0.0) \\
0(0.0) \\
1(100.0)\end{array}$ & $\begin{array}{l}0(0.0) \\
0(0.0) \\
0(0.0) \\
0(0.0) \\
0(0.0) \\
(100.0)\end{array}$ & $\begin{array}{c}2(3.2) \\
7(11.1) \\
1(1.6) \\
18(28.6) \\
12(19.0) \\
23(32.0)\end{array}$ & 0.857 \\
\hline $\begin{array}{c}\text { Age } \\
\text { 20-30 years old } \\
31-40 \text { years old } \\
41-50 \text { years old } \\
>51 \text { years old }\end{array}$ & $\begin{array}{c}0(0.0) \\
0(0.0) \\
0(0.0) \\
1(100.0)\end{array}$ & $\begin{array}{c}0(0.0) \\
1(50.0) \\
0(0.0) \\
1(50.0)\end{array}$ & $\begin{array}{c}2(3.2) \\
1(1.6) \\
11(17.5) \\
49(77.8)\end{array}$ & 0.198 \\
\hline $\begin{array}{c}\text { Number of FNAB Punctures } \\
\qquad 2 \text { times } \\
>2 \text { times }\end{array}$ & $\begin{array}{l}1(1.6) \\
0(0.0)\end{array}$ & $\begin{array}{l}2(3.2) \\
0(0.0)\end{array}$ & $\begin{array}{l}59(95.2) \\
4(100.0)\end{array}$ & 1.000 \\
\hline $\begin{array}{c}\text { Number of CNB Punctures } \\
2 \text { times } \\
>2 \text { times }\end{array}$ & $\begin{array}{l}0(0.0) \\
1(4.2)\end{array}$ & $\begin{array}{l}0(0.0) \\
2(8.3)\end{array}$ & $\begin{array}{c}42(100.0) \\
21(87.5)\end{array}$ & 0.040 \\
\hline
\end{tabular}


Table 4. Correlation of lung tumor location with FNAB and CNB techniques

\begin{tabular}{|c|c|c|c|c|c|c|c|c|}
\hline \multirow{2}{*}{ Variable } & \multicolumn{3}{|c|}{ FNAB } & \multirow[b]{2}{*}{ p } & \multicolumn{3}{|c|}{$\mathrm{CNB}$} & \multirow[b]{2}{*}{$\mathbf{p}$} \\
\hline & Malignation & $\begin{array}{c}\text { Non } \\
\text { malignant }\end{array}$ & $\begin{array}{l}\text { Undia- } \\
\text { gnosed }\end{array}$ & & Malignation & $\begin{array}{c}\text { Non } \\
\text { malignant }\end{array}$ & $\begin{array}{l}\text { Undia- } \\
\text { gnosed }\end{array}$ & \\
\hline Tumor size & & & & \multirow{7}{*}{0.757} & & & & \multirow{7}{*}{0.510} \\
\hline $21-30 \mathrm{~mm}$ & $0(0.0)$ & $1(10.0)$ & $1(5.6)$ & & $0(0.0)$ & $2(13.3)$ & $0(0.0)$ & \\
\hline $31-40 \mathrm{~mm}$ & $3(7.9)$ & $2(20.0)$ & $2(11.1)$ & & $4(8.5)$ & $3(20.0)$ & $0(0.0)$ & \\
\hline $41-50 \mathrm{~mm}$ & $1(2.6)$ & $0(0.0)$ & $0(0.0)$ & & $1(2.1)$ & $0(0.0)$ & $0(0.0)$ & \\
\hline $51-60 \mathrm{~mm}$ & $11(28.9)$ & $2(20.0)$ & $5(27.8)$ & & $14(29.8)$ & $2(13.3)$ & $2(50.0)$ & \\
\hline $61-70 \mathrm{~mm}$ & $8(21.0)$ & $1(10.0)$ & $3(16.7)$ & & $8(19.1)$ & $3(20.0)$ & $0(0.0)$ & \\
\hline$>70 \mathrm{~mm}$ & $15(39.5)$ & $4(40.0)$ & $7(38.9)$ & & 19 (40.4) & $5(33.3)$ & $2(50.0)$ & \\
\hline $\begin{array}{l}\text { Location of } \\
\text { the Lung }\end{array}$ & & & & \multirow{12}{*}{0.306} & & & & \multirow{12}{*}{0.240} \\
\hline $\begin{array}{l}\text { Right lung } \\
\text { superior lobe }\end{array}$ & & & & & & & & \\
\hline $\begin{array}{c}\text { Right } \\
\text { pulmonary }\end{array}$ & & & & & & & & \\
\hline & $15(39.5)$ & $3(30.0)$ & $5(27.8)$ & & $16(34.4)$ & $4(26.7)$ & $3(75.0)$ & \\
\hline lobe of the & $4(10.5)$ & $1(10.0)$ & $1(5.6)$ & & $6(12.8)$ & $0(0.0)$ & $0(0.0)$ & \\
\hline right lung & $2(5.3)$ & $1(10.0)$ & $3(16.7)$ & & $3(6.4)$ & $3(20.0)$ & $0(0.0)$ & \\
\hline Left superior & $13(34.2)$ & $3(30.0)$ & $4(22.0)$ & & $15(31.9)$ & $5(33.3)$ & $0(0.0)$ & \\
\hline lobe of the & $1(2.6)$ & $0(0.0)$ & $1(5.6)$ & & $1(2.1)$ & $1(6.7)$ & $0(0.0)$ & \\
\hline lung & $0(0.0)$ & $2(20.0)$ & $3(16.7)$ & & $2(4.3)$ & $2(13.3)$ & $1(25.0)$ & \\
\hline $\begin{array}{c}\text { Left } \\
\text { pulmonary } \\
\text { inferior lobe }\end{array}$ & $3(7.9)$ & $0(0.0)$ & $1(5.6)$ & & $4(8.5)$ & $0(0.0)$ & $0(0.0)$ & \\
\hline $\begin{array}{c}>1 \text { right lung } \\
\text { lobe }\end{array}$ & & & & & & & & \\
\hline $\begin{array}{c}>1 \text { left lung } \\
\text { lobe }\end{array}$ & & & & & & & & \\
\hline
\end{tabular}

*Kappa test results obtained results $\mathrm{K}=0.43 ; \mathrm{p}<0.001$

\section{Discussion}

What factors can increase the diagnostic value of trantoracial biopsy and prove the safety of thoracic ultrasound in guiding CNB in peripheral lung tumors, chest wall tumors, anterior mediastinal lesions. The size of the lesion does not appear to affect the diagnostic accuracy with thoracic ultrasound as a guide, however, the diagnostic rate is decreased in lesions located close to the ribs and is influenced by the respiratory movements of the patient and there are no serious complications from this procedure ${ }^{(7)}$.
CNB was significantly higher in preparing adequate material than that of FNAB. The adequate material for FNAB was found to be correlated with tumor size. Increasing the number of passes (needle pass away) in the FNAB technique is reported to increase the material to be more adequate. Operators' flight hours in univariate analysis were reported to play a role in providing adequate material. The FNAB specimen at $35 \mathrm{~mm}$ lesion size was reported to be sufficient to obtain specimens to be used for molecular follow-up tests. On the other hand, direct assessment by direct on-site anatomical pathology 
may be the best way to ensure sample adequacy ${ }^{(8)}$.

The diagnostic accuracy of the tansthoracic biopsy material is significantly affected by the size of the lesion, the accuracy will decrease in lesions smaller $\leq 20 \mathrm{~mm}$ and the accuracy will be increased in lesions $\geq 50 \mathrm{~mm}$ in size. The larger the lesion, the greater the chance that the tumor tissue or cells will experience necrosis, so the more likely the specimen is inadequate to make a definitive diagnosis. In fact, thoracic ultrasound cannot identify the incidence of necrosis of a tumor lesion, so the strategy for sampling large lesions is to target the biopsy area at the periphery to avoid the central area of the lung mass where the likelihood of the area of necrosis is high. The rate of presence of necrosis in lesions measuring $\leq 20 \mathrm{~mm}, 21-49 \mathrm{~mm}$ and $\geq 50 \mathrm{~mm}$ was $3.9 \%, 11.7 \%$ and $28.8 \%$, respectively ${ }^{(9)}$.

The diagnostic accuracy of the transthoracic biopsy will decrease with the size of the lung tumor. Small lesions may have decreased accuracy probably because if the size of the lesion is small it is possible for the lesion to move during the respiratory phase so that the needle fails to accurately target the lesion throughout the patient's respiration cycle $\mathrm{e}^{(5,8,10)}$.

The location and size of the tumor lesion will affect the accuracy of the FNAB. A good location for the FNAB technique if the tumor lesion is peripherally large. The location of the lung tumor in the superior lobe is easier to reach the biopsy needle with a straight needle angle, this position makes it easier for the needle to collect material without having to change the pleural space $^{(11)}$. The location of the mass attached to the pleura will also cause less movement during respiration, which can improve accuracy ${ }^{(11,12)}$.

In this study, there was no correlation between age, lesion size and the number of FNAB trajectories on the incidence of complications. Based on the study by Capalbo reported age as a factor influencing complications, with the incidence of pneumothorax due to CNB being reported in the majority of young subjects, parenchymal bleeding in the elderly and more complications in the right lung. $50 \%$ of pneumothorax cases occur in the superior lung lobe with CNB technique, $40 \%$ of parenchymal hemorrhage in the inferior lobe in FNAB. In terms of size, the CNB technique was more complicated than FNAB in lesions less than $3.5 \mathrm{~cm}$ in size. However, it is different from our research that Capalbo's study did not perform biopsy simultaneously so that we can find out in detail the incidence of complications for each technique. Parameters associated with complications were needle access, lesion size, age, needle diameter, and number of needle passes. With regard to age, complications of pulmonary parenchymal hemorrhage and hemoptysis occur more frequently in old age for those undergoing $\mathrm{CNB}$, possibly because elderly patients are usually on anticoagulant therapy because of cormorbid disease. There was no significant correlation between the number of passes with complications and diagnostic accuracy because the average success was only 1 pass, in contrast to other studies that pneumothorax was more common in those who underwent a large number of passes because this could result in a number of trauma to the pleura so required in the future to hold the coaxial needle ${ }^{(13)}$.

\section{Conclusion}

The majority of study subjects were male, aged more than 50 years, chronic cough was the most respiratory symptom, the majority of the distribution of tumors was in the superior lobe of the right lung, the majority of tumor size was $>70 \mathrm{~mm}$, and dominant needle access was from the anterior direction, with the most pathology results. Pulmonary adenocarcinoma. There was no correlation between lung tumor size and pathological anatomical findings with each of the biopsy techniques. There was no correlation between the location of lung tumors and the findings of the pathology anatomy in each of the biopsy techniques. There was no correlation between tumor size, age and number of FNAB needle passes and the incidence of each complication. There appears to be a significant correlation between the numbers of CNB needle passes more than 2 passes to the incidence of complications. Obtained a sufficient level of conformity between the CNB and FNAB results with a Kappa coefficient of 0.43 or $43 \%$ obtained a significance value of $p<0.001$ with an accuracy of $69.69 \%$. 


\section{Funding: None.}

Conflict of Interest: The authors declare that they have no conflict of interest.

Ethical Approval: We have conducted an ethical approval base on Declaration of Helsinki at Ethical Committee in Dr. Soetomo General Academic Hospital, Surabaya, Indonesia (1575/KEPK/X/2019).

\section{References}

1. Joudeh AA, Shareef SQ, Al-Abbadi MA. FineNeedle Aspiration Followed by Core-Needle Biopsy in the Same Setting: Modifying Our Approach. Acta cytologica. 2016;60(1):1-13.

2. Diacon AH, Theron J, Bolliger CT. Transthoracic ultrasound for the pulmonologist. Current opinion in pulmonary medicine. 2005;11(4):307-12.

3. Jeon KN, Bae K, Park MJ, Choi HC, Shin HS, Shin S, et al. US-guided transthoracic biopsy of peripheral lung lesions: pleural contact length influences diagnostic yield. Acta radiologica (Stockholm, Sweden : 1987). 2014;55(3):295-301.

4. Fu Y, Zhang Y-Y, Cui L-G, Tan S, Sun Y. Ultrasound-Guided Biopsy of Pleural-Based Pulmonary Lesions by Injection of ContrastEnhancing Drugs. Front Pharmacol. 2019;10:960-.

5. Manhire A, Charig M, Clelland C, Gleeson F, Miller $\mathrm{R}$, Moss $\mathrm{H}$, et al. Guidelines for radiologically guided lung biopsy. Thorax. 2003;58(11):920-36.

6. Jain D. Tru-cut/core Biopsy versus FNAC: Pulmonary Tumors. Journal of cytology. 2018;35(3):183-6.

7. Yamamoto N, Watanabe $T$, Yamada K, Nakai T, Suzumura T, Sakagami K, et al. Efficacy and safety of ultrasound (US) guided percutaneous needle biopsy for peripheral lung or pleural lesion: comparison with computed tomography (CT) guided needle biopsy. Journal of thoracic disease. 2019;11(3):936-43.

8. Layfield LJ, Roy-Chowdhuri S, Baloch Z, Ehya $\mathrm{H}$, Geisinger K, Hsiao SJ, et al. Utilization of ancillary studies in the cytologic diagnosis of respiratory lesions: The papanicolaou society of cytopathology consensus recommendations for respiratory cytology. Diagnostic cytopathology. 2016;44(12):1000-9.

9. Padmanabhan V, Steinmetz HB, Rizzo EJ, Erskine AJ, Fairbank TL, de Abreu FB, et al. Improving Adequacy of Small Biopsy and Fine-Needle Aspiration Specimens for Molecular Testing by Next-Generation Sequencing in Patients With Lung Cancer: A Quality Improvement Study at Dartmouth-Hitchcock Medical Center. Archives of pathology \& laboratory medicine. 2017;141(3):4029.

10. Merinda V, Soegiarto G, Wulandari L. T790M mutations identified by circulating tumor DNA test in lung adenocarcinoma patients who progressed on first-line epidermal growth factor receptor-tyrosine kinase inhibitors. Lung India : official organ of Indian Chest Society. 2020;37(1):13-8.

11. Meyer CA. "Transthoracic Needle Aspiration Biopsy of Benign and Malignant Lung Lesions"-A Commentary. American Journal of Roentgenology. 2007;188(4):891-3.

12. Ohno $\mathrm{Y}$, Hatabu H, Takenaka D, Higashino $\mathrm{T}$, Watanabe H, Ohbayashi C, et al. CT-guided transthoracic needle aspiration biopsy of small $(<$ or $=20 \mathrm{~mm})$ solitary pulmonary nodules. AJR American journal of roentgenology. 2003;180(6):1665-9.

13. Capalbo E, Peli M, Lovisatti M, Cosentino M, Mariani P, Berti E, et al. Trans-thoracic biopsy of lung lesions: FNAB or CNB? Our experience and review of the literature. La Radiologia medica. 2014;119(8):572-94. 